\title{
A new record of Wolbachia in the elephant ticks from Thailand
}

\author{
Supanee Hirunkanokpun ${ }^{\mathrm{a}}$, Arunee Ahantarig ${ }^{\mathrm{b}, \mathrm{c}}$, Visut Baimai ${ }^{\mathrm{b}, \mathrm{c}}$, Wachareeporn Trinachartvanit ${ }^{\mathrm{b}, *}$ \\ a Department of Biology, Faculty of Science, Ramkhamhaeng University, Ramkhamhaeng Road, \\ Bangkok 10240 Thailand \\ b Biodiversity Research Cluster, Department of Biology, Faculty of Science, Mahidol University, \\ Rama 6 Road, Bangkok 10400 Thailand \\ c Centre of Excellence for Vectors and Vector-Borne Diseases, Faculty of Science, \\ Mahidol University at Salaya, Phutthamonthon 4 Road, Nakhon Pathom 73170 Thailand
}

*Corresponding author, e-mail: wachareeporn.tri@mahidol.ac.th

Received 15 Dec 2017

Accepted 17 Dec 2017

\begin{abstract}
A new record of Wolbachia has been reported and characterized for the first time in ticks associated with the Asiatic elephant, Elephas maximas, in Prachuap Khiri Khan Province, Thailand. It was found in one pool of the Rhipicephalus microplus larvae based on PCR amplification and DNA sequencing of the partial 16S rRNA gene. The phylogenetic relationships among the Wolbachia identified in this study and other 21 Wolbachia from supergroups A-I were inferred through comparison of partial sequences of the 16S rRNA gene. Interestingly, this Wolbachia strain was closely related to those from supergroup A found in Ixodes ricinus ticks. Our findings warrant further investigation as this Wolbachia has a potential use for the biological control of ticks in this region.
\end{abstract}

KEYWORDS: Rhipicephalus microplus, Asiatic elephant, phylogenetic analysis

\section{INTRODUCTION}

Ticks are important vectors of bacteria, viruses, and protozoa which are zoonotic infectious agents in humans and animals. Ticks are prevalent throughout the world feeding on terrestrial vertebrates. Most hard ticks go through four life stages and require three blood meals from different types of host species to complete all developmental stages ${ }^{1}$. Hence they may acquire various pathogens and spread among vertebrate host species. In addition to pathogenic microorganisms, ticks are known to harbour symbionts that may affect host tick biology and reproduction. The endosymbiont Wolbachia is an obligate intracellular bacterium that is commonly found in arthropods and nematodes ${ }^{2}$. They are transmitted vertically from mother to offspring and manipulate the reproduction of their hosts, especially in some insects, including the induction of cytoplasmic incompatibility, parthenogenesis, feminization, and male killing ${ }^{1}$.

Four genera of hard ticks and one genus of soft ticks have been found on the Asiatic elephant (Elephas maximas) to date, i.e., Amblyomma, Haemaphysalis, Ixodes, Rhipicephalus, and Ornithodoros ${ }^{3-5}$. Three of Rhipicephalus ticks were described in Thai- land ${ }^{6}$. There are several vertebrate hosts that are fed upon by Rhipicephalus ticks, such as heck cattle (Bos domesticus), sambar deer (Cervus unicolor), humans (Homo sapiens), black rats (Rattus rattus), greater bandicoot rat (Bandicota indica), and bird (Garrulax leucolophus) ${ }^{6}$. However, no Rhipicephalus ticks have not been reported on Asiatic elephants in Thailand.

Although Wolbachia is widespread in many species of arthropods, little is known about Wolbachia in ticks. Only a few genera of ticks have been reported to be infected with Wolbachia endosymbionts, including Ixodes ${ }^{7}$, Haemaphysalis ${ }^{8}$, and Amblyomma ${ }^{9}$. However, no Rhipicephalus ticks have been reported on Asiatic elephants in Thailand. In this report, we present a new record of Wolbachia in Rhipicephalus microplus ticks collected from Asiatic elephant bong using PCR amplification and DNA sequencing. We also present a phylogenetic analysis of partial 16S rRNA sequences from this Wolbachia.

\section{MATERIALS AND METHODS}

\section{Tick collection}

A total of 9 ticks were collected from elephant bong (E. maximas) in Prachuap Khiri Khan Province, 
Thailand, in January 2014. These ticks were placed in a glass bottle containing 70\% ethanol. Two ticks in the nymphal stage and 7 larvae were identified as Rhipicephalus microplus based on their external morphological characteristics ${ }^{10}$. No adult tick was found in this study.

\section{DNA extraction and detection of Wolbachia via PCR amplification}

Ticks were washed twice in 70\% ethanol and once in $10 \%$ sodium hypochlorite, then rinsed three times in sterile distilled water. Genomic DNA (gDNA) was extracted from each nymph tick and each pool of larvae (three or four larvae per pool) using the QIAamp DNA Extraction Kit for Tissue (QIAGEN) according to the manufacturer's protocol. The quality of tick DNA samples was evaluated via PCR amplification of the tick mitochondrial 16S rRNA gene as previously described by Black and Piesman ${ }^{11}$. PCR assays targeting the 16S rRNA gene of Wolbachia were performed with the primers EHR16SD 5'-GG TACCYACAGAAGAAGTCC $-3^{\prime}$ and EHR16SR $5^{\prime}$-TAG CACTCATCGTTTACAGC $-3^{\prime}$, which amplify a $345 \mathrm{bp}$ fragment ${ }^{12}$. The PCR amplicon from the positive sample was purified using the High Pure PCR Product Purification Kit (Roche) and sequenced in an $A B I$ automated sequencer (Applied Biosystems).

\section{Phylogenetic analysis}

To identify the supergroup of the Wolbachia sequence amplified from Rhipicephalus microplus, Wolbachia 16S rRNA reference sequences from different supergroups were downloaded from GenBank. Multiple alignment was performed with MegAlign (DNAstar, Lasergene). Phylogenetic analysis was conducted using PAUP $4.0 \mathrm{~b} 1^{13}$. A maximum parsimony tree was constructed via a heuristic search using General Search Options. Confidence values for individual branches of the resulting tree were determined through bootstrap analysis with 1000 replicates.

\section{RESULTS}

The Wolbachia DNA was detectable in one pooled Rhipicephalus microplus larval samples. The $16 \mathrm{~S}$ rRNA primers resulted in an amplification product of $345 \mathrm{bp}$. The nucleotide sequence of the Wolbachia 16S rRNA fragment detected from the pool of Rhipicephalus microplus larvae has been submitted to GenBank under accession number KP231288.

The partial 16S rRNA sequences of Wolbachia detected in this study were used to construct a Wolbachia phylogeny based on comparison with $21 \mathrm{Wol}$ - bachia reference sequences from 9 different supergroups and one outgroup clade consisting of Haemaphysalis longicornis symbiont A and Arsenophonus from Nasonia vitripennis (Fig. 1). Based on this gene sequence, the Wolbachia from Rhipicephalus microplus ticks was grouped within supergroup A endosymbionts from Ixodes scapularis, Diprion pini, Aphis hederae, and Muscidifurax unirapter (Fig. 1).

\section{DISCUSSION}

Rhipicephalus ticks have been reported as important vectors of many pathogens, such as Rickettsia ${ }^{14}$, Ehrlichia $^{15}$, and Coxiella ${ }^{16}$. In this study, we provide the first report of Wolbachia in Rhipicephalus microplus ticks (larval stage) associated with Asiatic elephant in Thailand. Although Wolbachia infections have been reported in many species of insects, there are only a few cases of its infection in ticks, for example, I. scapularis ${ }^{7}$, Haemaphysalis hystricis ${ }^{8}$ and Amblyomma americanum ${ }^{9}$. Nevertheless, we have been investigating the endosymbiont Wolbachia pipientis in ticks occurring in Thailand, all of them showed negative results ${ }^{17,18}$. Hence our findings in this study indicate the important role of the Wolbachia host range in Thailand.

Different Wolbachia strains (also known as Wolbachia supergroups) have been classified from distinct genetic lineages of a single species of $W$. pipientis using DNA sequencing data. Thus far, phylogenetic analyses based on the sequences of the 16S rRNA, ftsZ, groEL, coxA, and gltA genes have divided $W$. pipientis into 16 supergroups ${ }^{19}$. Phylogenetic analysis based on the partial 16S rRNA gene sequence of Wolbachia obtained from Rhipicephalus microplus larvae in this study indicated that it belongs to the supergroup A. The roles of different Wolbachia supergroups in their arthropod hosts are variable, ranging from mutualism to acting as reproductive parasites. In the hymenopteran M. unirapter, thelytoky parthenogenesis is induced by Wolbachia, resulting in the production of diploid offspring by virgin females, without fertilization ${ }^{20}$. In mosquitoes, Wolbachia reduces arboviral transmission to humans by inhibiting viral replication ${ }^{21}$. Wolbachia have been reported in ticks with unknown consequences. However, a mutualistic relationship between Wolbachia and their host ticks has been proposed ${ }^{22}$. The effect of the Wolbachia detected in Rhipicephalus microplus host ticks in our study is still unknown. Thus further investigation of the interactions between Rhipicephalus microplus ticks and the Wolbachia supergroup A, especially in the adult life stage, would lead to better under- 


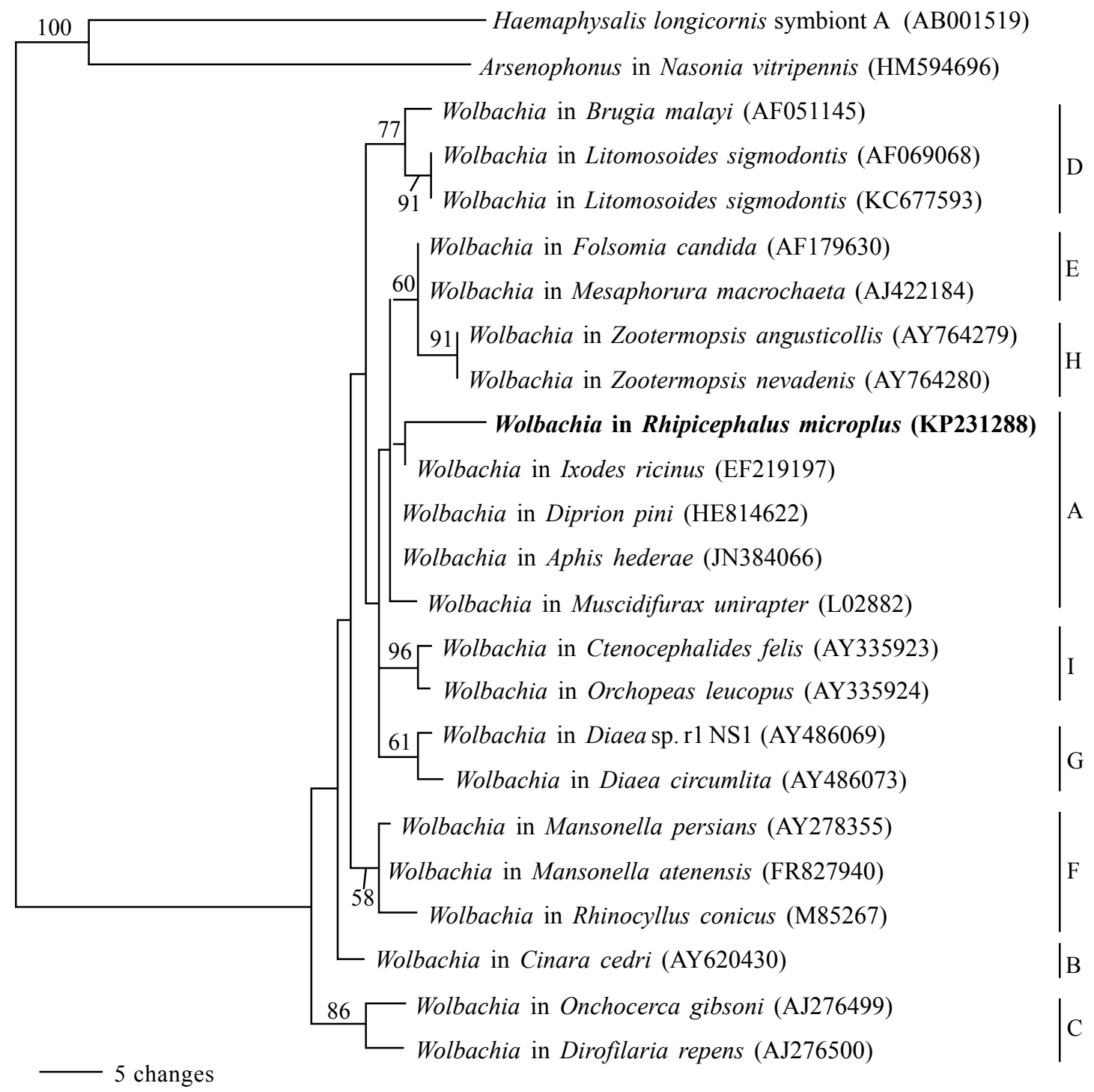

Fig. 1 Phylogenetic analysis based on the partial Wolbachia 16S rRNA sequence amplified from the elephant tick, Rhipicephalus microplus (bold). The tree was constructed using PAUP 4.0b1 software via maximum-parsimony analysis. The bootstrap values were replicated 1000 times, and only bootstrap percentages higher than 50\% are shown.

standing of coevolution. In addition, examination of Wolbachia infection status, localization, and transmission mechanism of this bacterium as well as the associated host reproductive phenotype should be carried out in order to develop an efficient control measure for tick-borne diseases in this region.

Acknowledgements: We thank all staffs at Biodiversity Research Cluster, Department of Biology, Faculty of Science, Mahidol University for their technical assistance. This study project is supported by Mahidol University, a Higher Education Research Promotion and a grant from BDC PERDO (BDC-PG2-160008), Thailand.

\section{REFERENCES}

1. Sonenshine DE (1991) Biology of Ticks, vol 1, Oxford Univ Press, New York.

2. Werren JH (1997) Biology of Wolbachia. Annu Rev Entomol 42, 587-609.

3. Chandrasekharan K (1992) Prevalence of infectious diseases in elephants in Kerala and their treatment. In: Silas EG, Nair MK, Nirmalan G (eds) The Asian Elephant: Ecology, Biology, Disease, Conservation and Management, Kerala Agricultural Univ, Trichur, pp 148-55.

4. Chandrasekharan K, Radhakrishnan K, Cheeran JV, Muraleedharan Nair KN, Prabhakaran T (1995) Re- 
view of the incidence, etiology and control of common diseases of Asian elephants with special reference to Kerala. In: Daniel JC, Datye HS (eds) $A$ Week with Elephants: Proceedings of the International Seminar on the Conservation of Elephant, Bombay Natural History Society, Oxford Univ Press, Bombay, pp 439-49.

5. Dilrukshi PRMP (2006) Taxonomic status of ticks in Sri Lanka. In: Bambaradeniya CBN (ed) The Fauna of Sri Lanka Status of Taxonomy, Research and Conservation, IUCN Sri Lanka, The World Conservation Union and Government of Sri Lanka, Colombo, pp 65-9.

6. Tanskul P, Stark HE, Inlao I (1983) A checklist of ticks of Thailand (Acari: Metastigmata: Ixodoidea). J Med Entomol 20, 330-41.

7. Benson MJ, Gawronski JD, Eveleigh DE, Benson DR (2004) Intracellular symbionts and other bacteria associated with deer ticks (Ixodes scapularis) from Nantucket and Wellfleet, Cape Cod, Massachusetts. Appl Environ Microbiol 70, 616-20.

8. Khoo JJ, Chen F, Kho KL, Ahmad Shanizza AI, Lim FS, Tan KK, Chang LY, AbuBakar S (2016) Bacterial community in Haemaphysalis ticks of domesticated animals from the Orang Asli communities in Malaysia. Ticks Tick Borne Dis 7, 929-37.

9. Zhang X, Norris DE, Rasgon JL (2011) Distribution and molecular characterization of Wolbachia endosymbionts and filarial nematodes in Maryland populations of the lone star tick (Amblyomma americanum). FEMS Microbiol Ecol 77, 50-6.

10. Walker AR, Bouattour A, Camicas JL, Estrada-Peña A, Horak IG, Latif AA, Pegram RG, Preston PM (2003) Ticks of Domestic Animals in Africa: a Guide to Identification of Species, Bioscience Reports, Edinburgh, UK.

11. Black WC, Piesman J (1994) Phylogeny of hard- and soft-tick taxa (Acari: Ixodida) based on mitochondrial 16S rDNA sequences. Proc Natl Acad Sci USA 91, 10034-8.

12. Parola P, Roux V, Camicas JL, Baradji I, Brouqui P, Raoult D (2000) Detection of ehrlichiae in African ticks by polymerase chain reaction. Trans Roy Soc Trop Med Hyg 94, 707-8.

13. Swofford DL (1999) PAUP*: Phylogenetic Analysis Using Parsimany (*and Other methods). Version 4. Sinauer Associates. Sunderland, MA.

14. Qiu Y, Nakao R, Thu MJ, Akter S, Alam MZ, Kato S, Katakura K, Sugimoto C (2016) Molecular evidence of spotted fever group rickettsiae and Anaplasmataceae from ticks and stray dogs in Bangladesh. Parasitol Res 115, 949-55.

15. Ndip LM, Ndip RN, Ndive VE, Awuh JA, Walker DH, McBride JW (2007) Ehrlichia species in Rhipicephalus sanguineus ticks in Cameroon. Vector Borne Zoonotic Dis 7, 221-7.

16. Muramatsu Y, Usaki N, Thongchai C, Kramomtong I, Kriengsak P, Tamura Y (2014) Seroepidemiologic survey in Thailand of Coxiella burnetii infection in cattle and chickens and presence in ticks attached to dairy cattle. Southeast Asian J Trop Med Publ Health 45, 1167-72.

17. Hirunkanokpun S, Kittayapong P, Cornet JP, Gonzalez JP (2003) Molecular evidence for novel tickassociated spotted fever group rickettsiae from Thailand. J Med Entomol 40, 230-7.

18. Ahantarig A, Malaisri P, Hirunkanokpun S, Sumrandee C, Trinachartvanit W, Baimai V (2011) Detection of Rickettsia and a novel Haemaphysalis shimoga symbiont bacterium in ticks in Thailand. Curr Microbiol 62, 1496-502.

19. Glowska E, Dragun-Damian A, Dabert M, Gerth M (2015) New Wolbachia supergroups detected in quill mites (Acari: Syringophilidae). Infect Genet Evol 30, 140-6.

20. Gottlieb Y, Zchori-Fein E, Werren JH, Karr TL (2002) Diploidy restoration in Wolbachia-infected Muscidifurax uniraptor (Hymenoptera: Pteromalidae). J Invertebr Pathol 81, 166-74.

21. Moreira LA, Iturbe-Ormaetxe I, Jeffery JA, Lu G, Pyke AT, Hedges LM, Rocha BC, Hall-Mendelin S, et al (2009) A Wolbachia symbiont in Aedes aegypti limits infection with dengue, Chikungunya, and Plasmodium. Cell 139, 1268-78.

22. Noda H, Munderloh UG, Kurtti TJ (1997) Endosymbionts of ticks and their relationship to Wolbachia spp. and tick-borne pathogens of human and animals. Appl Environ Microbiol 63, 3926-32. 